Article

\title{
An Advanced Forest Fire Danger Forecasting System: Integration of Remote Sensing and Historical Sources of Ignition Data
}

\author{
Masoud Abdollahi ${ }^{1}$, Tanvir Islam ${ }^{2}$, Anil Gupta ${ }^{1,3}$ and Quazi K. Hassan ${ }^{1, *}$ \\ 1 Department of Geomatics Engineering, Schulich School of Engineering, University of Calgary, \\ 2500 University Dr. NW, Calgary, AB T2N 1N4, Canada; abdolahi@ucalgary.ca (M.A.); \\ anil.gupta@gov.ab.ca (A.G.) \\ 2 NASA Jet Propulsion Laboratory, 4800 Oak Grove Drive, Pasadena, CA 91109, USA; \\ tanvir.islam@jpl.nasa.gov \\ 3 Alberta Environment and Parks, 293811 Street NE, Calgary, AB T2E 7L7, Canada \\ * Correspondence: qhassan@ucalgary.ca; Tel.: +1-403-220-9494
}

Received: 20 May 2018; Accepted: 11 June 2018; Published: 12 June 2018

\begin{abstract}
Forest fire is one of the major natural hazards/disasters in Canada and many ecosystems across the world. Here, our objective was to enhance the performance of an existing solely remote sensing-based forest fire danger forecasting system (FFDFS), and its implementation over the northern region of the Canadian province of Alberta. The modified FFDFS was comprised of Moderate Resolution Imaging Spectroradiometer (MODIS)-derived daily surface temperature (Ts) and precipitable water (PW), and 8-day composite of normalized difference vegetation index (NDVI) and normalized difference water index (NDWI), where we assumed that cloud-contaminant pixels would reduce the risk of fire occurrences. In addition, we generated ignition cause-specific static fire danger (SFD) maps derived using the historical human- and lightning-caused fires during the period 1961-2014. Upon incorporating different combinations of the generated SFD maps with the modified FFDFS, we evaluated their performances against actual fire spots during the 2009-2011 fire seasons. Our findings revealed that our proposed modifications were quite effective and the modified FFDFS captured almost the same amount of fires as the original FFDFS, i.e., about 77\% of the detected fires on an average in the top three fire danger classes of extremely high, very high, and high categories, where about $50 \%$ of the study area fell under low and moderate danger classes. Additionally, we observed that the combination of modified FFDFS and human-caused SFD map (road buffer) demonstrated the most effective results in fire detection, i.e., $82 \%$ of detected fires on an average in the top three fire danger classes, where about $46 \%$ of the study area fell under the moderate and low danger categories. We believe that our developments would be helpful to manage the forest fire in order to reduce its overall impact.
\end{abstract}

Keywords: human-caused static fire danger map; lightning-caused static fire danger map; normalized difference vegetation index; normalized difference water index; precipitable water; surface temperature

\section{Introduction}

Forest fires are an integral part of ecosystems across the globe, including those in the Canadian boreal region. In general, forest fires are perceived negatively for several reasons, such as: (i) loss of forestry revenues [1]; (ii) expedition of global warming through releasing of carbon dioxide into the atmosphere [2]; (iii) destruction of neighborhoods, critical infrastructure, and biodiversity [3]; and (iv) increase in respiratory diseases though deteriorating air quality [4], etc. At the same time, 
there are some positive aspects including reviving healthy trees, extinguishing pests and diseases, and providing nutrients for better regeneration. In order to quantify the balance between negative and positive impacts, it is extremely important to have an efficient system to manage forest fires. In this context, one of the critical steps to understanding the pre-fire conditions is the need of formulating a forest fire danger forecasting system, which would be possible by using remote sensing-based approaches.

In recent decades, researchers have used satellite-based remote sensing approaches to study fire danger conditions as remote sensors can acquire data continuously even in the remote areas of the landscape. In general, we can divide the remote sensing-based approaches broadly into two categories, such as monitoring systems that determine the fire danger conditions during and/or after fire occurrences [5-7]; and forecasting systems that predict the fire danger conditions before fire occurrences $[1,8,9]$. In fact, the forecasting systems should be studied more extensively as the monitoring systems are not useful for the operational forest fire management purposes [10]. Some of the key studies are summarized as follows:

- Preisler et al. [11] employed the AVHRR-derived relative greenness (RG) and normalized difference vegetation index (NDVI) in calculating fire potential index (FPI) to determine the weekly distributions of three fire-related components (i.e., the total number of fires, total fires with a specific size, and probability of those fires which have a certain size) over the continental United States during the period 1985-2005. In determining the probability, they used two types of FPI values (i.e., $\mathrm{FPI}_{10}$ and $\mathrm{FPI}_{1000}$ obtained from 10 -h and 1000-h time lag fuel moisture, respectively). Upon generating the probabilities, they compared the forecasted number of large fires and observed ones. The result showed that both FPI 10 and $\mathrm{FPI}_{1000}$ could predict large fires.

- Bisquert et al. [12] used Moderate Resolution Imaging Spectroradiometer (MODIS)-derived 16-day enhanced vegetation index (EVI) at $250 \mathrm{~m}$ spatial resolution, and daily surface temperature (Ts) at $1 \mathrm{~km}$ spatial resolution to predict fire danger condition over the Galicia region, Spain during the period 2001-2006. They evaluated different combinations of input variables (e.g., difference between two 16-day images for EVI; average and maximum 2 to 16-day composites, and differences between two Ts images in the same composite period, and so on) along with fire history and period of year using logistic regression and artificial neural networks. They found the best predictor (i.e., combination of 8-day Ts images, fire history in each cell, and period of year) was able to classify $65 \%$ of the observed fires in the high fire danger class.

- Chowdhury and Hassan [8] employed MODIS-derived products, such as 8-day composites of Ts at $1 \mathrm{~km}$, NDVI and normalized multiband drought index (NMDI) at $500 \mathrm{~m}$, and daily precipitable water (PW) at $1 \mathrm{~km}$ resolution to develop a Forest Fire Danger Forecasting System (FFDFS). They forecasted the fire danger conditions at daily scale over the forest areas in Alberta during 2009-2011 in five fire danger classes (i.e., low, moderate, high, very high, and extremely high), and demonstrated that $\sim 77.39 \%$ of the fire events fell into the high to extremely high categories. Note that this study was based on the earlier research conducted in the Earth Observation Laboratory at The University of Calgary, and was focused on forecasting fire dangers at 8-day time-scale [1,13].

- Li et al. [14] studied MODIS-derived 16-day composites of RG and vegetation danger index (VDI) at a $250 \mathrm{~m}$ spatial resolution in conjunction with historical fire events in order to determine fire danger conditions over Northern China for the period 2008-2011. They compared RG and VDI values for fire spot locations at three times: (i) before the fire (2008 and 2009); (ii) during the fire events (2010); and (iii) after fire occurrence (2011). They showed that RG values were more than $70 \%$ at the fire spot locations before the fire occurring, and VDI values were positive.

- Liu et al. [15] used: (i) MODIS-derived 8-day Ts and surface reflectance data; (ii) Advanced Spaceborne Thermal Emission and Reflection Radiometer (ASTER)-derived digital elevation model (DEM) at $30 \mathrm{~m}$ spatial resolution; and (iii) historical lightning-caused fire data to generate the potential fire risk at a $0.5^{\circ} \times 0.5^{\circ}$ spatial resolution over a mountainous area in China during the period 2000-2006. They produced five fire risk classes (i.e., low to extremely high); and found 
that $\sim 68.8 \%$ of the historical fires fell under the three fire risk classes (i.e., relatively high, high, and extremely high).

- Arganaraz et al. [16] employed MODIS-derived 8-day vegetation and canopy water content-related indices (e.g., NDVI, EVI, and normalized difference water index (NDWI), etc.) to estimate live fuel moisture content (LFMC) and, subsequently, to predict fire danger conditions within different land cover classes in the forest area of Gran Chaco in Argentina during three fire seasons (i.e., 2003, 2012, and 2013). Then, they classified the modeled LFMC values into four fire danger classes (i.e., low, moderate, high, and extremely high) at a monthly scale, and observed that $\sim 60 \%$ of the burn pixels contained high and extremely high danger classes.

- Yu et al. [17] used: (i) MODIS-derived 8-day Ts at $1 \mathrm{~km}$, surface reflectance at $500 \mathrm{~m}$, and fire mask at $1 \mathrm{~km}$ data; (ii) Shuttle Radar Topography Mission (SRTM)-derived DEM at $30 \mathrm{~m}$; and (iii) Tropical Rainfall Measuring Mission (TRMM)-derived 8-day accumulated precipitation data at $0.25^{\circ} \times 0.25^{\circ}$, to forecast fire risk at a 8-day scale in Cambodia. They reported that the predicted risk in comparison to the MODIS-derived fire spots had good agreement (i.e., $\mathrm{r}^{2} \approx 0.987$ ).

In general, most of the above-mentioned systems had either coarse spatial or temporal resolutions. In contrast, Chowdhury and Hassan's proposed method had not only demonstrated its ability to forecast danger conditions at daily time-scales with $500 \mathrm{~m}$ spatial resolution, but also over Canadian boreal forested regions. Despite this, it had several issues, such as: (i) only one variable (i.e., PW) was available on a daily time-scale; (ii) it applied a gap-filling algorithm [13] to infill the cloud-contaminant pixels that was not only time consuming, but also unable to eliminate all the cloudy pixels; and (iii) it did not incorporate the source of ignition, including lightning- and human-caused fires, in the makeup of the system. In order to address these issues, our objectives were three-fold. Firstly, we exploited historical fire occurrences caused by both lightning and human activities in order to generate cause-specific static fire danger (SFD) maps. Secondly, we opted to enhance the legerity of the existing system (i.e., FFDFS) described in our earlier studies $[1,8,13]$ by: (a) employing a daily-scale Ts; (b) removing the gap-filling algorithm upon the assumption that the cloud-contaminant pixels would exhibit low fire danger conditions; and (c) replacing the NMDI using NDWI, as this would be simpler to compute. Finally, we combined the remote sensing-based danger conditions (as outlined in the first step) with the two SFD maps, and evaluated their overall achievements.

\section{Materials}

\subsection{Study Area}

Our study area is located between $52-60^{\circ} \mathrm{N}$ latitudes and $110-120^{\circ} \mathrm{W}$ longitudes in the northern part of the Canadian province of Alberta (see Figure 1). Since our goal was to forecast fire danger in the forest areas, we focused on four different forest land cover types mentioned in Table 1 . The elevation in this area varies between 162 and $3596 \mathrm{~m}$ above mean sea level, and the mean annual temperature and precipitation vary from -3.6 to $1.1^{\circ} \mathrm{C}$, and between $377-535 \mathrm{~mm}$, respectively. Thus, the area is known for short summers, and long and cold winters in the area [18].

\subsection{Data Requirement}

In this study, we employed three datasets including four different products from Terra MODIS, 54-years of fire occurrence data (see Figure 2), and two geographic information system (GIS) layers (roads and natural subregions; Table 1). Of the natural subregions we selected 17 natural subregions in generating the fire ignition source SFD maps. The reason we chose these subregions was that they had experienced at least one fire during the period 1961-2014 (Figure 1). 


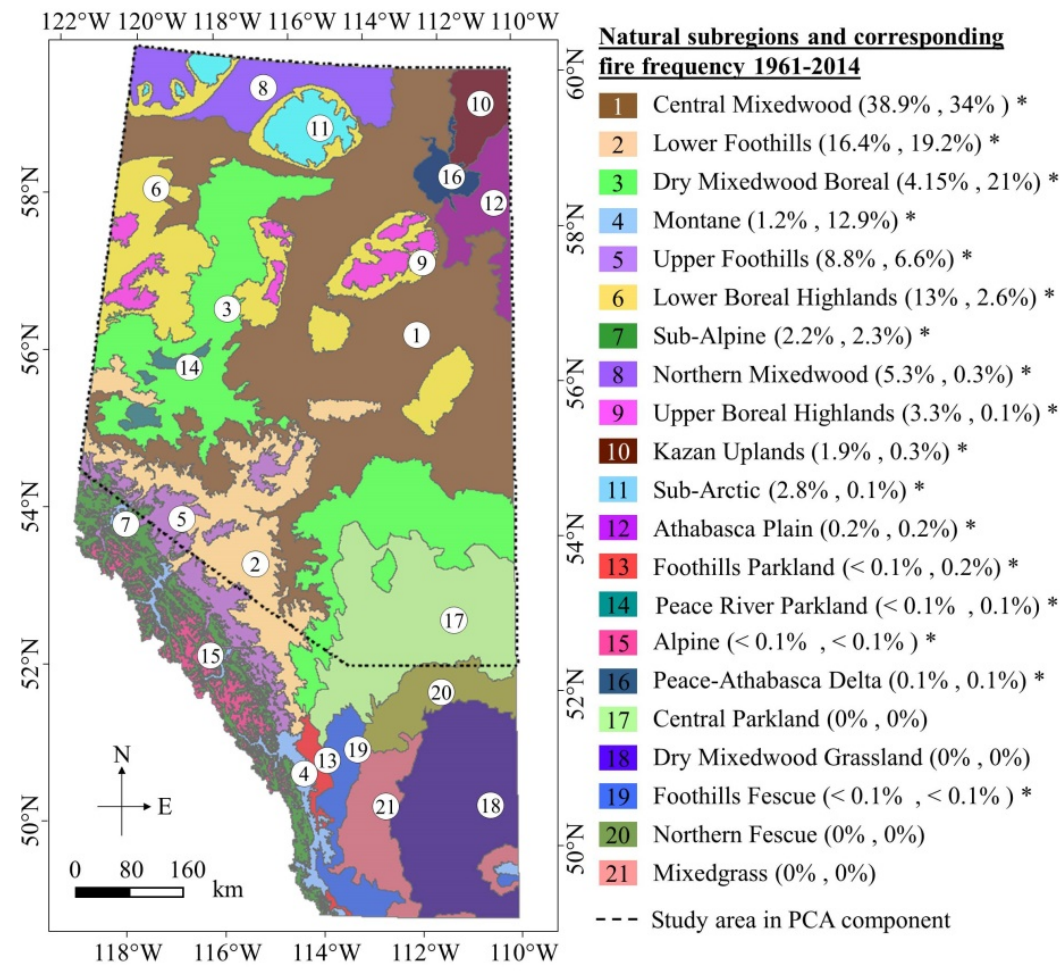

Figure 1. Map illustrating the location of the study area, and fire frequency (percentage of lightningand human-caused in parenthesis, respectively) in all 21 natural subregions during the period of 1961-2014 in Alberta, Canada. The asterisk marks denote the subregions where we observed at least one fire occurrence during the period of interest.

Table 1. Description of the employed datasets in the scope of this study.






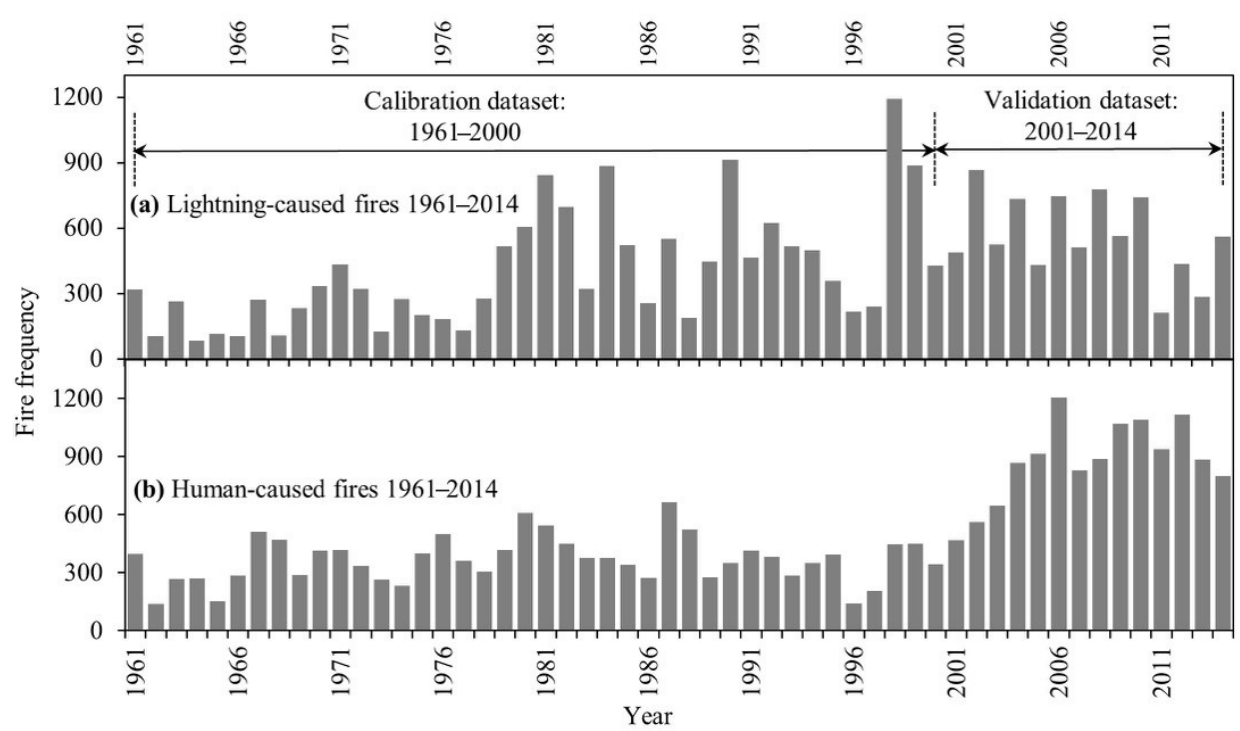

Figure 2. Frequency distribution of the (a) lightning- and (b) human-caused fire occurrences in 17 natural subregions of Alberta from 1961-2014.

\section{Methods}

Our proposed method included three major components (Figure 3) including: (i) generating of fire ignition source-based SFD maps; (ii) enhancing the performance of FFDFS; and (iii) incorporating SFD maps with enhanced FFDFS and validations.

Enhancing the performance of existing RS-based system (FFDFS)

Generating Static Fire Danger (SFD) maps

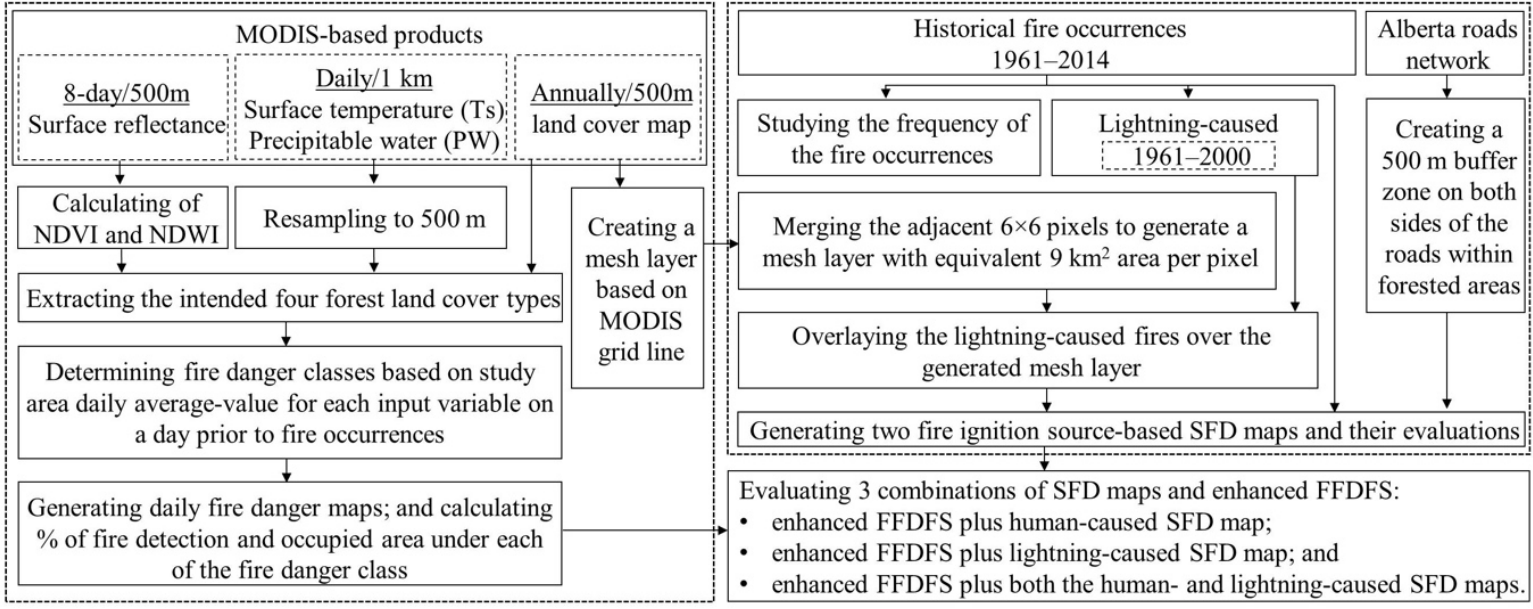

Figure 3. Schematic diagram of the enhanced forest fire danger forecasting system.

\subsection{Generating of Fire Ignition Source-Based SFD Maps}

In general, people use road networks to visit parks, campgrounds, and other recreation facilities, and also to commute to the municipalities and industrial zones located within forested regions; as such, the chance of forest fire occurrences increases in the vicinity of the roads network [19-21]. Thus, we created a $500 \mathrm{~m}$ buffer zone on both sides of the roads located within four forest land cover types (Table 1). We then produced a human-caused SFD map with two classes, a high danger class inside the buffer zone, and a low danger class outside the buffer zone.

In studying the spatio-temporal patterns of lightning-caused fire incidents, Krawchuk et al. [22] divided Alberta's central-eastern landscape into $10 \mathrm{~km}^{2}$ cells for the period 1983-1993. We used a cell 
size with an area of $9 \mathrm{~km}^{2}$ for 1961-2000 within forested areas of Alberta. We hypothesized that the lightning-caused fires might follow a specific spatial distribution pattern over a long period of time which might be used as a base to generate a SFD map. To do so, we took the following four steps: (i) we created a mesh layer based on MODIS grid line at $500 \mathrm{~m}$ spatial resolution; (ii) we merged the adjacent pixels in this mesh layer in order to generate a mesh layer with equivalent $9 \mathrm{~km}^{2}$ (i.e., $6 \times 6$ pixels or $3 \mathrm{~km}$ spatial resolution) area per pixel; (iii) we masked the generated mesh layers using four forest land cover types in Alberta; and (iv) finally, we overlaid the lightning-caused fire spots during the period 1961-2000 over the generated mesh layer in order to create a SFD map; which had two classes, i.e., (i) high danger classes where at least one fire happened during the period 1961-2000; and (ii) low danger classes where no fire happened over the same time period.

\subsection{Enhancing the Performance of FFDFS and Their Validations}

Upon implementing the proposed modifications on FFDFS, we generated daily fire danger maps based on the existing framework described in Chowdhury and Hassan [8] (Figure 4). In this process, we clipped the model inputs (i.e., 8-day composites of surface reflectance, daily Ts and PW) within the forested areas described in Table 1 . Then, using surface reflectance data during the 8 -day period $(j)$, we calculated 8-day composites of NDVI and NDWI for our study area in the same period of time (i.e., $\mathrm{NDVI}_{j}, \mathrm{NDWI}_{j}$ ). These two vegetation indices were employed as synthetic daily indices in the model over the next 8 -day period $(j+1)$ assuming that vegetation greenness and water content changes would be negligible in such a short period of time. Using the two types of variables per day (i.e., actual daily $\mathrm{Ts}_{i}$ and $\mathrm{PW}_{i}$; synthetic daily $\mathrm{NDVI}_{j}$ and $\mathrm{NDWI}_{j}$ ), we then calculated the study area daily average-value for each input variable in $i$ day (i.e., $\overline{\mathrm{Ts}_{i}}, \overline{\mathrm{PW}_{i}}, \overline{\mathrm{NDVI}_{j}}, \overline{\mathrm{NDWI}_{j}}$ ). Then, by comparing the variable specific-value at a given pixel within our study area in $i$ day (i.e., $\mathrm{Ts}_{i}, \mathrm{PW}_{i}, \mathrm{NDVI}_{j}$, $\mathrm{NDWI}_{j}$ ) with the daily average-value in the whole study area for the relevant variable in the same day (i.e., calculated in previous step), we classified each input variable during the $i$ day into two fire danger classes (i.e., high or low) assuming that the following conditions might support fire occurrence:

- $\quad$ higher temperature than daily average (i.e., $\mathrm{Ts}_{i} \geq \overline{\mathrm{Ts}_{i}}$ );

- lower precipitable water than daily average (i.e., $\mathrm{PW}_{i} \leq \overline{\mathrm{PW}_{i}}$ );

- lower level of vegetation greenness than daily average (i.e., $\mathrm{NDVI}_{j} \leq \overline{\mathrm{NDVI}_{j}}$ ); or

- lower vegetation water content than daily average (i.e., $\mathrm{NDWI}_{j} \leq \overline{\mathrm{NDWI}_{j}}$ ).

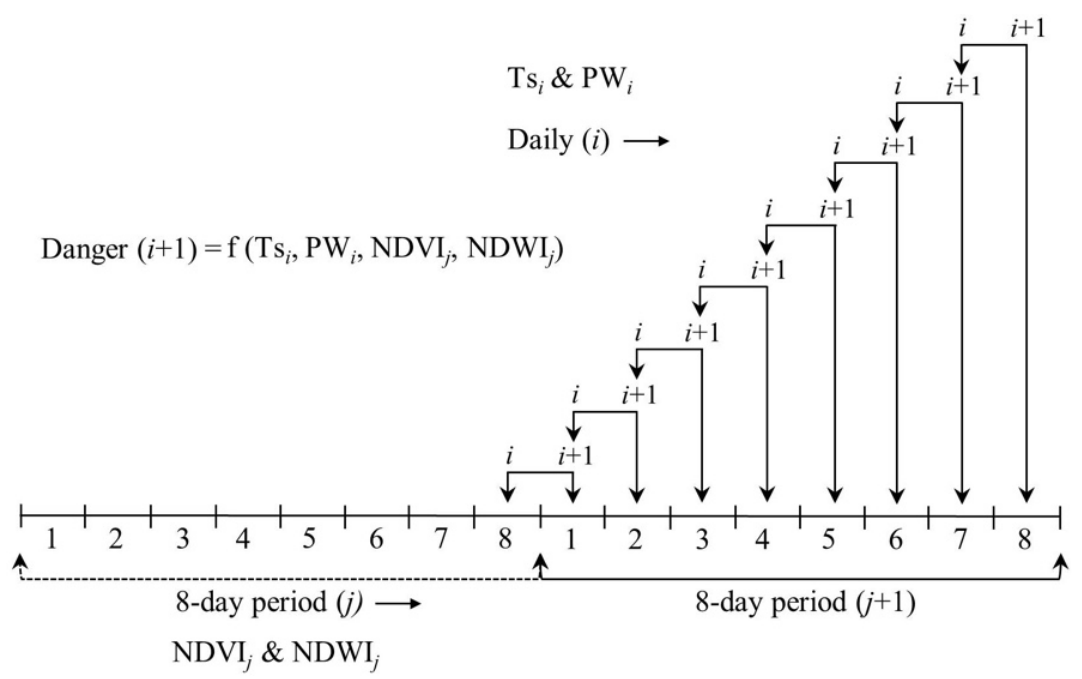

Figure 4. The schematic diagram of employed method, along with characteristics of danger condition in day $(i+1)$ using the model input variables including: actual daily surface temperature $\left(\mathrm{Ts}_{i}\right)$ and precipitable water $\left(\mathrm{PW}_{i}\right)$; and synthetic daily normalized difference vegetation index $\left(\mathrm{NDVI}_{j}\right)$ and normalized difference water index $\left(\mathrm{NDWI}_{j}\right)$. 
Finally, we combined these fire danger classes in $i$ day in order to generate fire danger map for next day (i.e., $i+1$ ). The generated fire danger map consisted of five classes: (i) extremely high, where all four input variables were classified as high fire danger; (ii) very high, where at least three input variables were classified as high fire danger; (iii) high, where at least two of the input variables were classified as high fire danger; (iv) moderate, where at least one of the input variables was classified as high fire danger; and (v) low, where none of the four input variables were classified as high fire danger.

\subsection{Incorporating SFD Maps with Enhanced FFDFS}

We incorporated the SFD maps (described in Section 3.2) with the enhanced FFDFS in order to modify the generated daily fire danger maps in Section 3.1. As such, we evaluated these combinations:

(i) enhanced FFDFS plus human-caused SFD map;

(ii) enhanced FFDFS plus lightning-caused SFD map; and

(iii) enhanced FFDFS plus both the human- and lightning-caused SFD maps.

In such modifications, we assigned the generated fire danger classes into a higher class where the SFD maps showed "high fire danger" conditions. However, the generated fire danger classes remained unchanged where the SFD maps showed "low fire danger" conditions. Using the new combinations, we generated a new set of daily fire danger maps in order to forecast fire danger conditions.

In order to determine the best combination of remote sensing-based data and SFD maps in forecasting forest fire danger conditions, we evaluated the remote sensing-based daily fire danger maps (i.e., generated in Section 3.2), and enhanced ones based on the SFD maps by overlaying the ground-based forest fire spots during the period 2009-2011. In this case, we calculated both the percentage of detected fires and the daily occupied area by each fire danger class. Note that in the evaluation phase, we employed those fire spots that burned an area equal to, or greater than, 1 hectare, because a burned area of less than 1 hectare might not be detected by the spatial resolution employed in this study (i.e., $500 \mathrm{~m}$ ). Upon evaluating the daily fire danger maps, we compared those with the results reported by Chowdhury and Hassan [8] in order to find the best system in forecasting forest fire danger conditions.

\section{Results and Discussion}

\subsection{Generating of Fire Ignition Source-Based SFD Maps}

We compared both the human- (i.e., road buffer) and lightning-based SFD maps against the ground-based forest fire spots during the periods of 1961-2014 and 2001-2014, respectively (Figure 5). We found that $65.3 \%$ and $78.8 \%$ of the fires occurred within the high danger class of the human-caused SFD on an average during the periods 1961-2000 and 2001-2014, respectively, while $87.8 \%$ and $12.2 \%$ of the study area fell under the low and high danger classes, respectively. It is interesting to note that the historical human-caused fires during the period 1961-2014 showed an increasing trend since 2001 (Figure 2). In fact, our analysis revealed that an increment of $13.5 \%$ (i.e., from $65.3 \%$ to $78.8 \%$ ) on average during the 2001-2014 period, in comparison to 1961-2000, occurred within the $500 \mathrm{~m}$ distance from the roads' center. This might be related to the fact that human accessibility to the forested areas increased due to several factors. Those included: (i) the expansion of the oil and gas companies' activities in the heart of forested lands; (ii) the establishment of more recreation facilities and camps near the roads; (iii) the relatively warmer weather; and (iv) cheaper vehicles to increase the number of visitors [20,23]. In addition, the observed results were similar to the literature that indicated road networks could be employed as a good indicator to detect human-caused fires [24,25]. 
(a) Human-caused SFD map

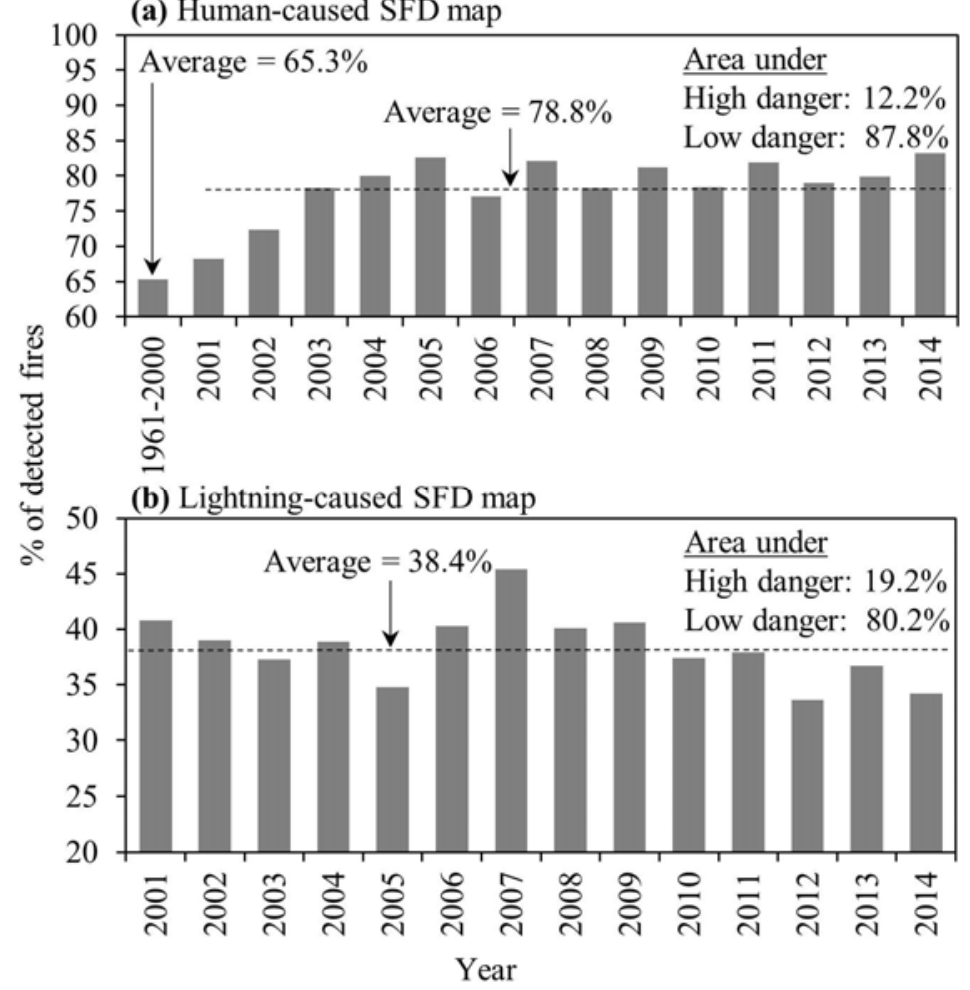

Figure 5. Dynamics of human- and lightning-caused SFD maps in terms of their percentage of detected fires and percentage of area under each of the danger classes.

In case of the lightning-caused SFD map, we observed that $38.4 \%$ of the fire events fell within the extent of the high danger class; while $80.8 \%$ and $19.2 \%$ of the study area fell under the low and high danger classes, respectively. Our findings of a relative smaller amount of detected fires would be quite normal due to the fact that the location of lightning strikes would be random as influenced by atmospheric conditions [22,26,27]. In addition, actual fire events would also depend on vegetation cover (in other words, fuel availability), their states, and fuel continuity [22,28-30].

\subsection{Enhacing the Remote Sensing-Based FFDFS and Its Incorporation with the SFD Maps}

Upon implementing the proposed modifications on the remote sensing-based FFDFS, and combining that with the $500 \mathrm{~m}$ road buffer and lightning-caused SFD map, we evaluated their performance against the ground-based forest fire spots during the period 2009-2011 fire seasons (Table 2). We found a reasonable amount of fires, i.e., about $77 \%$ of the fire events fell in the top three fire danger classes of extremely high, very high, and high categories (Table 2). In fact, our findings were quite similar in comparison to the outcome of the original FFDFS (i.e., about 77\%) reported in Chowdhury and Hassan [8]. We also calculated the areas under each of the fire danger classes, where about $50 \%$ of the study area fell under low and moderate danger classes (Table 3). We were unable to compare this result as Chowdhury and Hassan [8] did not report a similar analysis.

It is interesting to note that our proposed modifications were quite effective. For example, the use of cloud-contaminant pixels in the image as low danger reduced the computational time and no significant impact on the outcomes. In fact, another study reported a negative correlation between cloudiness and forest fire occurrences [31]. Additionally, the computation of NDWI was relatively simple, which was also used in describing fire danger conditions in other studies [16,32]. Finally, the time step of Ts, i.e., from 8-day to daily-scale, would be useful as the temperature would be known as more dynamic in the shorter time-scale. 
Table 2. Comparison of the modified FFDFS and its integration with road buffers and lightning-caused SFD maps against the ground-based forest fire spots in terms of fire detection performance.

\begin{tabular}{|c|c|c|c|c|c|c|c|c|c|c|c|}
\hline \multirow{3}{*}{ Year } & \multirow{3}{*}{ Danger Class } & \multicolumn{2}{|c|}{ Original FFDFS } & \multicolumn{2}{|c|}{ Modified FFDFS } & \multicolumn{2}{|c|}{ Modified FFDFS + Road Buffer } & \multicolumn{2}{|c|}{ Modified FFDFS + Lightning } & \multicolumn{2}{|c|}{$\begin{array}{l}\text { Modified FFDFS + Road } \\
\text { Buffer + Lightning }\end{array}$} \\
\hline & & \multicolumn{10}{|c|}{$\%$ of: } \\
\hline & & Detected Fires & Cumulative $(\downarrow)$ & Detected Fires & Cumulative $(\downarrow)$ & Detected Fires & Cumulative $(\downarrow)$ & Detected Fires & Cumulative $(\downarrow)$ & Detected Fires & Cumulative $(\downarrow)$ \\
\hline \multirow{5}{*}{2009} & Extremely High & 8.96 & 8.96 & 10.39 & 10.39 & 19.48 & 19.48 & 19.48 & 19.48 & 31.17 & 31.17 \\
\hline & Very High & 28.36 & 37.31 & 33.12 & 43.51 & 29.87 & 49.35 & 29.22 & 48.70 & 38.31 & 69.48 \\
\hline & High & 36.57 & 73.88 & 28.57 & 72.08 & 28.57 & 77.92 & 27.27 & 75.97 & 23.38 & 92.86 \\
\hline & Moderate & 20.90 & 94.78 & 22.73 & 94.81 & 18.18 & 96.10 & 20.78 & 96.75 & 7.14 & 100.00 \\
\hline & Low & 5.22 & 100.00 & 5.19 & 100.00 & 3.90 & 100.00 & 3.25 & 100.00 & 0.00 & 100.00 \\
\hline \multirow{5}{*}{2010} & Extremely High & 14.88 & 14.88 & 8.08 & 8.08 & 15.66 & 15.66 & 24.75 & 24.75 & 40.91 & 40.91 \\
\hline & Very High & 30.95 & 45.83 & 43.94 & 52.02 & 49.49 & 65.15 & 36.36 & 61.11 & 37.37 & 78.28 \\
\hline & High & 30.36 & 76.19 & 26.77 & 78.79 & 16.67 & 81.82 & 20.71 & 81.82 & 12.63 & 90.91 \\
\hline & Moderate & 19.64 & 95.83 & 15.66 & 94.44 & 12.63 & 94.44 & 15.15 & 96.97 & 8.59 & 99.49 \\
\hline & Low & 4.17 & 100.00 & 5.56 & 100.00 & 5.56 & 100.00 & 3.03 & 100.00 & 0.51 & 100.00 \\
\hline \multirow{5}{*}{2011} & Extremely High & 15.45 & 15.45 & 11.11 & 11.11 & 36.30 & 36.30 & 25.19 & 25.19 & 49.63 & 49.63 \\
\hline & Very High & 36.59 & 52.03 & 41.48 & 52.59 & 31.11 & 67.41 & 31.85 & 57.04 & 28.15 & 77.78 \\
\hline & High & 30.08 & 82.11 & 26.67 & 79.26 & 17.78 & 85.19 & 27.41 & 84.44 & 17.04 & 94.81 \\
\hline & Moderate & 13.82 & 95.93 & 14.07 & 93.33 & 8.89 & 94.07 & 10.37 & 94.81 & 5.19 & 100.00 \\
\hline & Low & 4.07 & 100.00 & 6.67 & 100.00 & 5.93 & 100.00 & 5.19 & 100.00 & 0.00 & 100.00 \\
\hline \multirow{5}{*}{ 2009-2011 } & Extremely High & 13.09 & 13.09 & 9.86 & 9.86 & 23.81 & 23.81 & 23.14 & 23.14 & 40.57 & 40.57 \\
\hline & Very High & 31.97 & 45.06 & 39.51 & 49.37 & 36.83 & 60.64 & 32.48 & 55.62 & 34.61 & 75.18 \\
\hline & High & 32.34 & 77.39 & 27.34 & 76.71 & 21.01 & 81.64 & 25.13 & 80.75 & 17.68 & 92.86 \\
\hline & Moderate & 18.12 & 95.51 & 17.49 & 94.19 & 13.23 & 94.87 & 15.43 & 96.18 & 6.97 & 99.83 \\
\hline & Low & 4.49 & 100.00 & 5.81 & 100.00 & 5.13 & 100.00 & 3.82 & 100.00 & 0.17 & 100.00 \\
\hline
\end{tabular}


Table 3. Comparison of the modified FFDFS and its integration with road buffers and lightning-caused SFD maps against the ground-based forest fire spots in terms of areas under the fire danger classes *.

\begin{tabular}{|c|c|c|c|c|c|c|c|c|c|}
\hline \multirow{2}{*}{ Year } & \multirow{2}{*}{ Danger Class } & \multicolumn{2}{|c|}{ Modified FFDFS } & \multicolumn{2}{|c|}{ Modified FFDFS + Road Buffer } & \multicolumn{2}{|c|}{ Modified FFDFS + Lightning } & \multicolumn{2}{|c|}{ Modified FFDFS + Road Buffer + Lightning } \\
\hline & & Area $(\%)$ & Cumulative $(\uparrow)$ & Area $(\%)$ & Cumulative ( $\uparrow)$ & Area $(\%)$ & Cumulative ( $\uparrow)$ & Area $(\%)$ & Cumulative ( $\uparrow)$ \\
\hline \multirow{5}{*}{2009} & Extremely High & 2.57 & 100.00 & 5.24 & 100.00 & 7.77 & 100.00 & 9.84 & 100.00 \\
\hline & Very High & 21.75 & 97.42 & 22.39 & 94.76 & 22.96 & 92.23 & 23.42 & 90.16 \\
\hline & High & 26.95 & 75.67 & 27.81 & 72.37 & 28.75 & 69.27 & 29.37 & 66.74 \\
\hline & Moderate & 34.72 & 48.72 & 32.10 & 44.56 & 29.71 & 40.52 & 27.72 & 37.37 \\
\hline & Low & 14.00 & 14.00 & 12.46 & 12.46 & 10.81 & 10.81 & 9.65 & 9.65 \\
\hline \multirow{5}{*}{2010} & Extremely High & 1.94 & 100.00 & 4.61 & 100.00 & 7.13 & 100.00 & 9.16 & 100.00 \\
\hline & Very High & 21.77 & 98.07 & 22.17 & 95.39 & 22.78 & 92.88 & 23.07 & 90.84 \\
\hline & High & 25.51 & 76.30 & 26.76 & 73.22 & 27.81 & 70.10 & 28.78 & 67.77 \\
\hline & Moderate & 36.13 & 50.79 & 33.58 & 46.46 & 30.99 & 42.29 & 29.05 & 38.99 \\
\hline & Low & 14.66 & 14.66 & 12.88 & 12.88 & 11.30 & 11.30 & 9.94 & 9.94 \\
\hline \multirow{5}{*}{2011} & Extremely High & 2.56 & 100.00 & 4.88 & 100.00 & 7.61 & 100.00 & 9.33 & 100.00 \\
\hline & Very High & 21.10 & 97.44 & 21.87 & 95.12 & 22.39 & 92.40 & 22.96 & 90.67 \\
\hline & High & 25.72 & 76.34 & 27.26 & 73.25 & 27.88 & 70.01 & 29.13 & 67.71 \\
\hline & Moderate & 35.98 & 50.62 & 33.20 & 45.99 & 30.76 & 42.13 & 28.66 & 38.58 \\
\hline & Low & 14.64 & 14.64 & 12.79 & 12.79 & 11.37 & 11.37 & 9.92 & 9.92 \\
\hline \multirow{5}{*}{ 2009-2011 } & Extremely High & 2.36 & 100.00 & 4.91 & 100.00 & 7.50 & 100.00 & 9.44 & 100.00 \\
\hline & Very High & 21.54 & 97.64 & 22.14 & 95.09 & 22.71 & 92.50 & 23.15 & 90.55 \\
\hline & High & 26.06 & 76.10 & 27.28 & 72.95 & 28.15 & 69.79 & 29.09 & 67.40 \\
\hline & Moderate & 35.61 & 50.04 & 32.96 & 45.67 & 30.48 & 41.64 & 28.47 & 38.31 \\
\hline & Low & 14.43 & 14.43 & 12.71 & 12.71 & 11.16 & 11.16 & 9.84 & 9.84 \\
\hline
\end{tabular}

* In the original FFDFS, Chowdhury and Hassan [8] did not report occupied aresa under each of the fire danger classes. 
Once we added the road buffer to the modified FFDFS, the amount of detected fires increased from about $77 \%$ to $82 \%$, which demonstrated the effectiveness of employing such a buffer zone around the road networks in detecting fire events. As a matter of fact, such an improvement was expected as roadsides would be used by the people for various activities, as described in Section 4.1. When we incorporated the lightning-caused SFD map with modified FFDFS, the amount of detected fires improved from about $77 \%$ to $81 \%$, which was similar to the addition of road buffer to the modified FFDFS. Finally, when we incorporated both road buffer and lightning-caused SFD map with the modified FFDFS, we observed a very large improvement, i.e., about $16 \%$ in the amount of detected fires by the system. In this case, about $93 \%$ of the fires fell in the top three fire danger classes, which were the highest among all the combinations evaluated. In addition to the amount of detected fires by each of the proposed combinations with the modified FFDFS, we also calculated the area under each of the fire danger classes in order to comprehend the system performance (Table 2). Then, we compared the area in the bottom two fire danger classes, i.e., moderate and low classes for the three combinations with the modified FFDFS. In this case, we found that the combination of the road buffer with the modified FFDFS was best, e.g., about $46 \%$ of the area fell under the low and moderate danger classes, which was about $4 \%$ less compared to that of the modified FFDFS. The decrease in overlap continued when we incorporated the lightning-caused SFD map with the modified FFDFS. In this case, the reduction happened from about 50\% to about $42 \%$. Finally, employing both the road buffer and lightning-caused SFD map with the modified FFDFS caused a decrease of $12 \%$ falling (i.e., from about 50\% to $38 \%$ ). The reason for the loss in area would be related to assigning the generated moderate fire danger class into a higher class where the human- (road buffer) and/or lightning-caused SFD maps showed a "high fire danger" condition. From an operational point of view, it would be highly desirable to keep more and more area under the low and moderate danger classes at the highest possible level. That way fire-fighting efforts could be concentrated over the top three fire danger classes of extremely high, very high, and high. Consequently, we considered that the incorporation of the human-caused SFD with the modified FFDFS was the best from an operational perspective.

Figure 6 shows an example of fire danger maps generated on 14 May 2011 by the modified remote sensing-based FFDFS using the individual variable (i.e., Ts, PW, NDVI, and NDWI)-specific danger conditions, which was then integrated with the human- (road buffer) and lightning-caused SFD maps. As the remote sensing-derived variables were dynamic in nature at daily (for Ts, and PW) and 8-day time scales (for NDVI, and NDWI), they would be the prime controller of the final outcomes depicted in Panels $\mathrm{A}, \mathrm{A}+\mathrm{B}, \mathrm{A}+\mathrm{C}$, and $\mathrm{A}+\mathrm{B}+\mathrm{C}$.

Despite, the reasonable performance of the modified FFDFS in conjunction with the road buffer-based SFD map, some of the fires, i.e., about 18\% on an average during 2009-2011 fell under the moderate and low fire danger classes. This issue could be improved by integrating other variables, such as: (a) vegetation phenological stages, as that would affect the fuel availability for fire occurrences [33]; (b) atmospheric conditions, as those would regulate the lightning strikes [22,26,27]; and (c) topographical features, as those might influence the vegetation conditions [34]. 
Fire danger maps based on individual input variables
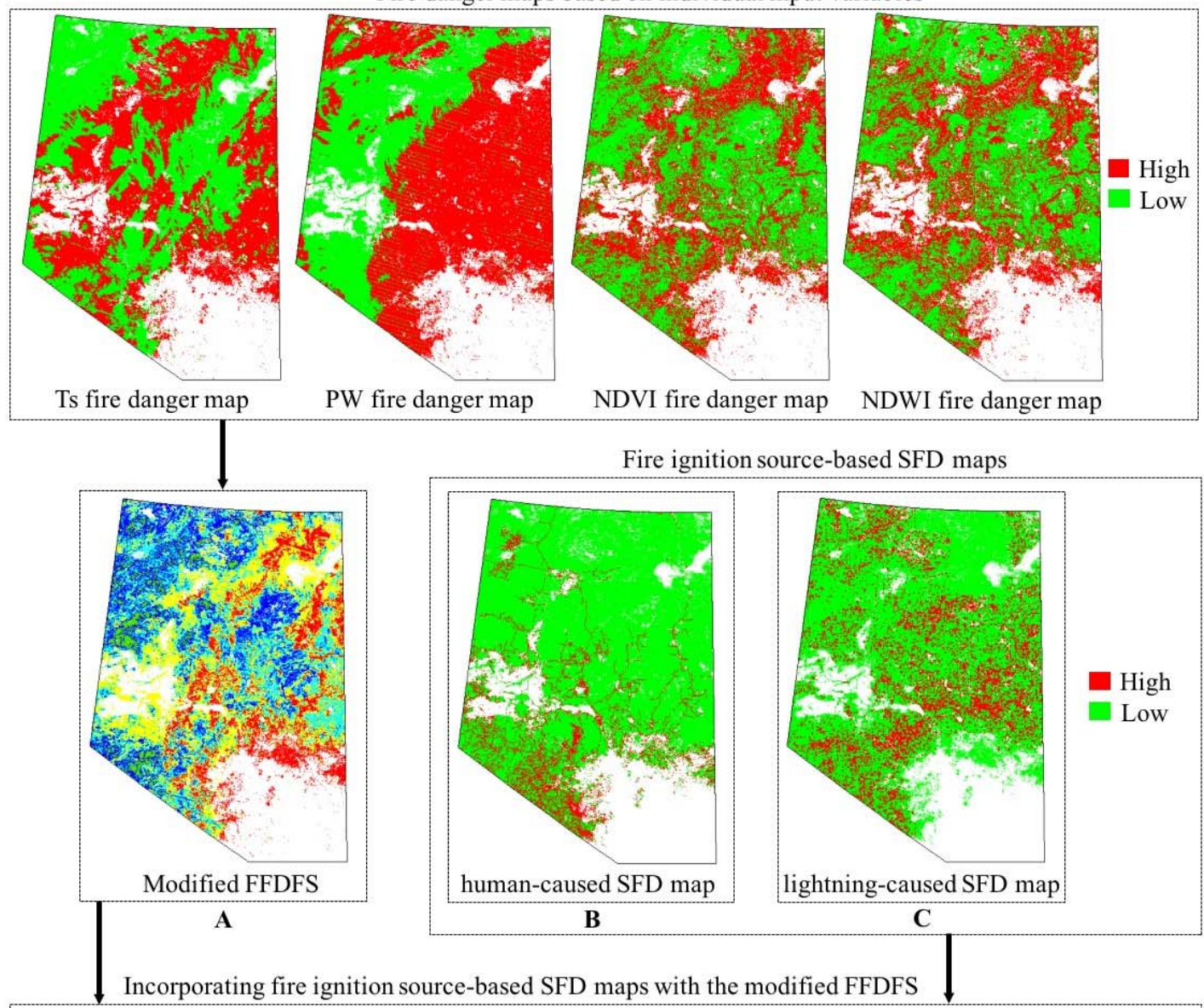

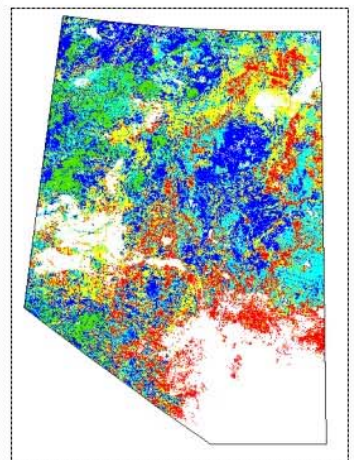

$\mathbf{A}+\mathbf{B}$

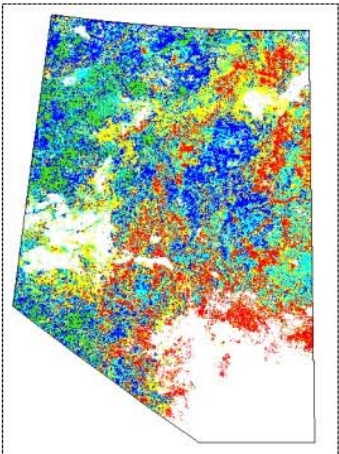

$\mathbf{A}+\mathbf{C}$

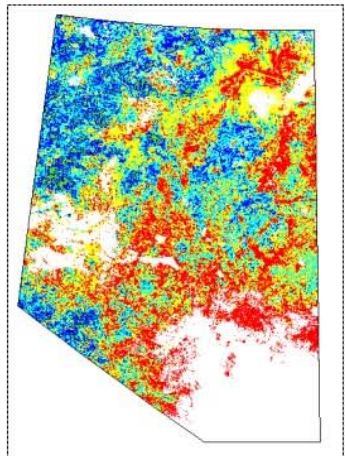

$\mathbf{A}+\mathbf{B}+\mathbf{C}$
Fire danger classes

May 14, 2011

Extremely high

Very high

High

Moderate

Low

Figure 6. Example of fire danger maps produced on 14 May 2011 by the modified remote sensing-based FFDFS using the individual variable (Ts, PW, NDVI, and NDWI)-specific danger conditions; which was then integrated with the human- and lightning-caused SFD maps.

\section{Concluding Remarks}

In this paper, we demonstrated a simple, but effective framework for forest fire danger forecasting and its implementation over the forested regions in the northern portion of Alberta. We first applied three modifications on the original FFDFS: (i) improving the temporal resolution of the employed Ts from 8-day to daily-scale; (ii) reducing the system computation time by removing the gap-filling algorithm upon assuming that the cloud-contaminant pixels would exhibit low fire danger conditions; and (iii) substituting the employed NMDI by a simpler vegetation index of NDWI. In addition, we evaluated the outcome of modified FFDFS by combining two fire ignitions source-based SFD maps 
derived from historical human- and lightning-caused fires during 1961-2014. Then we examined the outcomes of the different combinations against the actual fire spots during the fire seasons of 2009-2011. Among all of the combinations, we found that the integration of modified FFDFS and a road buffer (human-caused SFD map) demonstrated the most effective results in fire detection, i.e., about $82 \%$ on an average in the top three fire danger classes, where about $46 \%$ of the study area fell under the moderate and low danger categories. Despite these favourable results, we strongly recommend that our proposed system should be thoroughly evaluated before being implemented in other ecosystems in Canada and elsewhere in the world.

Author Contributions: Conceptualization: M.A. and Q.K.H.; formal analysis: M.A. and Q.K.H.; funding acquisition: M.A. and Q.K.H.; investigation: M.A., T.I., A.G., and Q.K.H.; methodology: M.A. and Q.K.H.; supervision: Q.K.H.; and validation: M.A. and Q.K.H.

Acknowledgments: This study was partially funded by the: (i) Ministry of Science, Research, and Technology of Iran via offering the PhD scholarship to M.A.; and (ii) Natural Sciences and Engineering Research Council of Canada Discovery Grant to Q.K.H. We would also like to thank NASA and Alberta Forest Service for providing MODIS and fire spots data, respectively, at free of cost.

Conflicts of Interest: The authors declare no conflict of interest.

\section{References}

1. Akther, M.S.; Hassan, Q.K. Remote Sensing-Based Assessment of Fire Danger Conditions Over Boreal Forest. IEEE J. Sel. Top. Appl. Earth Obs. Remote Sens. 2011, 4, 992-999. [CrossRef]

2. Booth, B.; Bellouin, N. Black carbon and atmospheric feedbacks. Nature 2015, 519, 167-168. [CrossRef] [PubMed]

3. Ahmed, M.R.; Rahaman, K.R.; Hassan, Q.K. Remote Sensing of Wildland Fire-Induced Risk Assessment at the Community Level. Sensors 2018, 18, 1570. [CrossRef] [PubMed]

4. Williamson, G.J.; Bowman, D.M.; Price, O.F.; Henderson, S.B.; Johnston, F.H. A transdisciplinary approach to understanding the health effects of wildfire and prescribed fire smoke regimes. Environ. Res. Lett. 2015, 11, 125009. [CrossRef]

5. Sow, M.; Mbow, C.; Hély, C.; Fensholt, R.; Sambou, B. Estimation of Herbaceous Fuel Moisture Content Using Vegetation Indices and Land Surface Temperature from MODIS Data. Remote Sens. 2013, 5, 2617-2638. [CrossRef]

6. Qi, Y.; Dennison, P.E.; Spencer, J.; Riano, D. Monitoring live fuel moisture using soil moisture and remote sensing proxies. Fire Ecol. 2012, 8, 71-87. [CrossRef]

7. Wang, L.; Qu, J.J.; Hao, X. Forest fire detection using the normalized multi-band drought index (NMDI) with satellite measurements. Agric. For. Meteorol. 2008, 148, 1767-1776. [CrossRef]

8. Chowdhury, E.H.; Hassan, Q.K. Development of a New Daily-Scale Forest Fire Danger Forecasting System Using Remote Sensing Data. Remote Sens. 2015, 7, 2431-2448. [CrossRef]

9. Bisquert, M.M.; Sánchez, J.M.; Caselles, V. Fire danger estimation from MODIS Enhanced Vegetation Index data: Application to Galicia region (north-west Spain). Int. J. Wildl. Fire 2011, 20, 465. [CrossRef]

10. Chowdhury, E.H.; Hassan, Q.K. Operational perspective of remote sensing-based forest fire danger forecasting systems. ISPRS J. Photogramm. Remote Sens. 2015, 104, 224-236. [CrossRef]

11. Preisler, H.K.; Burgan, R.E.; Eidenshink, J.C.; Klaver, J.M.; Klaver, R.W. Forecasting distributions of large federal-lands fires utilizing satellite and gridded weather information. Int. J. Wildl. Fire 2009, 18, 508-516. [CrossRef]

12. Bisquert, M.M.; Caselles, E.; Snchez, J.M.; Caselles, V. Application of artificial neural networks and logistic regression to the prediction of forest fire danger in Galicia using MODIS data. Int. J. Wildl. Fire 2012, 21, 1025-1029. [CrossRef]

13. Chowdhury, E.H.; Hassan, Q.K. Use of remote sensing-derived variables in developing a forest fire danger forecasting system. Nat. Hazards 2013, 67, 321-334. [CrossRef]

14. Li, X.; Lanorte, A.; Telesca, L.; Song, W.; Lasaponara, R. Assessment of MODIS-Based NDVI-Derived Index for Fire Susceptibility Estimation in Northern China. In Computational Science and Its Applications; Springer: Berlin, Germany, 2015; Volume 9155, pp. 193-203, ISBN 978-3-319-21469-6. 
15. Liu, W.; Wang, S.; Zhou, Y.; Wang, L.; Zhu, J.; Wang, F. Lightning-caused forest fire risk rating assessment based on case-based reasoning: A case study in DaXingAn Mountains of China. Nat. Hazards 2016, 81, 347-363. [CrossRef]

16. Arganaraz, J.P.; Landi, M.A.; Bravo, S.J.; Gavier-Pizarro, G.I.; Scavuzzo, C.M.; Bellis, L.M. Estimation of Live Fuel Moisture Content From MODIS Images for Fire Danger Assessment in Southern Gran Chaco. IEEE J. Sel. Top. Appl. Earth Obs. Remote Sens. 2016, 9, 5339-5349. [CrossRef]

17. Yu, B.; Chen, F.; Li, B.; Wang, L.; Wu, M. Fire Risk Prediction Using Remote Sensed Products: A Case of Cambodia. Photogramm. Eng. Remote Sens. 2017, 83, 19-25. [CrossRef]

18. Downing, D.J.; Pettapiece, W.W. Natural Regions and Subregions of Alberta; Government of Alberta: Edmonton, AB, Canada, 2006.

19. Costafreda-Aumedes, S.; Vega-Garcia, C. ANN multivariate analysis of factors that influence human-caused multiple fire starts. In Advances in Forest Fire Research; Imprensa da Universidade de Coimbra: Coimbra, Portugal, 2014; Volume 4, pp. 1787-1798, ISBN 9789892608846.

20. Wang, Y.; Anderson, K.R. An evaluation of spatial and temporal patterns of lightning- and human-caused forest fires in Alberta, Canada, 1980-2007. Int. J. Wildl. Fire 2010, 19, 1059-1072. [CrossRef]

21. Martínez, J.; Vega-Garcia, C.; Chuvieco, E. Human-caused wildfire risk rating for prevention planning in Spain. J. Environ. Manag. 2009, 90, 1241-1252. [CrossRef] [PubMed]

22. Krawchuk, M.A.; Cumming, S.G.; Flannigan, M.D.; Wein, R.W. Biotic and abiotic regulation of lightning fire inititation in the mixedwood boreal forest. Ecology 2006, 87, 458-468. [CrossRef] [PubMed]

23. Camp, P.E.; Krawchuk, M.A. Spatially varying constraints of human-caused fire occurrence in British Columbia, Canada. Int. J. Wildl. Fire 2017, 26, 219-229. [CrossRef]

24. Guo, F.; Su, Z.; Wang, G.; Sun, L.; Lin, F.; Liu, A. Wildfire ignition in the forests of southeast China: Identifying drivers and spatial distribution to predict wildfire likelihood. Appl. Geogr. 2016, 66, 12-21. [CrossRef]

25. Adab, H.; Kanniah, K.D.; Solaimani, K.; Sallehuddin, R. Modelling static fire hazard in a semi-arid region using frequency analysis. Int. J. Wildl. Fire 2015, 24, 763-777. [CrossRef]

26. Abatzoglou, J.T.; Kolden, C.A.; Balch, J.K.; Bradley, B.A. Controls on interannual variability in lightning-caused fire activity in the western US. Environ. Res. Lett. 2016, 11. [CrossRef]

27. Podur, J.; Martell, D.L.; Csillag, F. Spatial patterns of lightning-caused forest fires in Ontario, 1976-1998. Ecol. Model. 2003, 164, 1-20. [CrossRef]

28. Frost, C. Presettlement fire frequency regimes of the United States: A first approximation. In Fire in Ecosystem Management: Shifting the Paradigm from Suppression to Prescription; Proceedings of the Tall Timbers Fire Ecology Conference, Tallahassee, FL, USA, 14-16 April 1998; Tall Timbers Research Station: Tallahassee, FL, USA, 1998; Volume 20, pp. 70-81.

29. Calef, M.P.; Varvak, A.; McGuire, A.D. Differences in human versus lightning fires between urban and rural areas of the boreal forest in interior Alaska. Forests 2017, 8, 422. [CrossRef]

30. Kilinc, M.; Beringer, J. The spatial and temporal distribution of lightning strikes and their relationship with vegetation type, elevation, and fire scars in the northern Territory. J. Clim. 2007, 20, 1161-1173. [CrossRef]

31. Živanovic, S.; Zigar, D. Monitoring of cloudiness in the function of the forests fire protection. Acta Agric. Serbica 2016, 41, 3-15. [CrossRef]

32. Bisquert, M.; Sánchez, J.; Caselles, V. Modeling Fire Danger in Galicia and Asturias (Spain) from MODIS Images. Remote Sens. 2014, 6, 540-554. [CrossRef]

33. De Angelis, A.; Bajocco, S.; Ricotta, C. Phenological variability drives the distribution of wildfires in Sardinia. Landsc. Ecol. 2012, 27, 1535-1545. [CrossRef]

34. Abdollahi, M.; Hassan, Q.K.; Chowdhury, E.H.; Gupta, A. Exploring the relationships between topographical elements and forest fire occurrences in Alberta, Canada. In Remote Sensing of Hydro-Meteorological Hazards; Petropoulos, G., Islam, T., Eds.; CRC Press: Boca Raton, FL, USA, 2017.

(C) 2018 by the authors. Licensee MDPI, Basel, Switzerland. This article is an open access article distributed under the terms and conditions of the Creative Commons Attribution (CC BY) license (http:/ / creativecommons.org/licenses/by/4.0/). 